\title{
In-situ Synthesis of WC/TaC Reinforced Nickel-Based Composite Alloy Coating by Laser Cladding
}

\author{
Yong Yaowei ${ }^{1,2}, \quad$ Fu Wei $^{3}, \quad$ Zhang Xiang ${ }^{1}, \quad$ Deng Qilin', $\quad$ Yang Jianguo ${ }^{1}$ \\ ${ }^{1}$ Shanghai Jiao Tong University, Shanghai 200240, China; ${ }^{2}$ Ningxia University, Yinchuan 750021 , China; ${ }^{3}$ State Key Laboratory of Advanced \\ Welding and Joining, Harbin Institute of Technology, Harbin 150001, China
}

\begin{abstract}
An in-situ synthesized WC/TaC reinforced nickel-based composite coatings have been fabricated on AISI 1045 mild carbon steel substrate by laser cladding of powder mixture of $\mathrm{Ni60} / \mathrm{WC}$ with $\mathrm{Ta}_{2} \mathrm{O}_{5}$ and graphite. The microstructure and hardness distribution of $\mathrm{WC} / \mathrm{TaC} / \mathrm{Ni} 60$ composite coating were investigated by scanning electron microscopy (SEM) and X-ray diffraction (XRD) techniques. Results show that the microstructure of the coating has a metallurgical bonding with substrate and is mainly composed of $\gamma$-Ni dendrites, $\mathrm{W}_{2} \mathrm{C}, M_{7} \mathrm{C}_{3}$ carbides, and dispersed $\mathrm{TaC}$ particles. The hardness HV of WC/TaC/Ni60 composite coating has been enhanced to a value similar to $9650 \mathrm{MPa}$, which is 1.3 times higher than that of Ni60 coating. Measurement results demonstrate that these improvements are attributed to the presence of in-situ synthesized $\mathrm{TaC}$ particles, microstructure change and phase variations.
\end{abstract}

Key words: laser cladding; nickel-based alloy; tantalum (Ta); tantalum carbide (TaC); tungsten carbide (WC)

Laser cladding is a promising technology aimed to produce new metallic coating with high performance, such as high hardness, excellent wear and corrosion resistance onto the surface of substrate ${ }^{[1]}$. High energy laser can melt the wide range of materials to form the desired surface while there is only very little thermal effect on the bulk of samples ${ }^{[2]}$. In the past decades, metal matrix composite has been widely used to generate the ceramic reinforced composite coating on various functional substrates. It is encouraged to develop new coating for enhanced properties of material and the requirement of industries. Since the stronger bond between coating and bulks can be produced by in-situ synthesized reinforcement, various carbides of refractory metals have been extensively used to synthesize the reinforced metal matrix composite coating such as $\mathrm{WC}^{[3]}, \mathrm{TiC}, \mathrm{ZrC}, \mathrm{VC}^{[4]}, \mathrm{NbC}^{[5]}$ and $\mathrm{TaC}^{[6]}$. With the in-situ reaction method, the reaction enforcements are more compatible with the matrix and more stable in thermodynamics. Meanwhile, such coating is more uniform ${ }^{[7]}$.

Among these studies, the refractory metal of Tantalum (Ta) is one of the strongest carbide formation element, which can easily react with carbon to generate a Tantalum carbide $(\mathrm{TaC})$ due to its free formation enthalpy $(143.7 \mathrm{~kJ} / \mathrm{mol})$. TaC possesses high hardness and melting point, superior chemical stability, good wear resistance and corrosion resistance ${ }^{[8]}$. Wang et al. ${ }^{[9]}$ synthesized $\mathrm{TaC}$ to improve the wear behaviors of $\mathrm{Ni}$ matrix by reacting $\mathrm{Ta}_{2} \mathrm{O}_{5}$ with graphite. Chao et al. ${ }^{[10]}$ also produced $\mathrm{TaC} / \mathrm{Ni60}$ coating by this means in laser cladding, and they found that the hardness was 1.38 times of $\mathrm{Ni}$ matrix, and the wear rate was reduced by a factor of five. $\mathrm{Yu}$ et al. studied the particle behaviors of $\mathrm{TaC}{ }^{[11]}$, and investigated the positive influence of $\mathrm{TaC}$ on the hardness ${ }^{[8]}$ and abrasive wear resistance of coating ${ }^{[6]}$. Similar to TaC, WC particle becomes a leading enhancement because of its metallic character and high hardness. However, the low free formation enthalpy makes it easily dissolvable, and consequently, the brittle $\eta$ phase may be generated in molten pool. Zhong et al. ${ }^{[12]}$ investigated laser cladding of a W/C/Ni powder blend on $40 \mathrm{Cr}$ steel substrate. The results showed that WC/Ni coating was formed by feeding the pure tungsten, carbon and nickel elements. Crack behavior of nickel-based

Received date: November 14, 2016

Foundation item: National Natural Science Foundation of China (51275303)

Corresponding author: Deng Qilin, Ph. D, Associate Professor, School of Mechanical Engineering, Shanghai Jiaotong University, Shanghai 200240, P. R. China, Tel: 0086-21-34206804, E-mail: dengqilin@sjtu.edu.cn

Copyright (C) 2017, Northwest Institute for Nonferrous Metal Research. Published by Elsevier BV. All rights reserved. 
WC coating was produced by Zhou et al. ${ }^{[3]}$, and they declaimed that the dissolution of WC would cause the cracks. Other researches showed that the reinforcement volume fraction and size had effects on the microstructure and thus the mechanical behaviors ${ }^{[13,14]}$, and therefore, the route of multi-compound will be a promising direction for improving the performance of coating, which can be compatible with the advantages of components.

In this work, the mixed powder of $\mathrm{Ta}_{2} \mathrm{O}_{5}$ and graphite is added to laser clad $\mathrm{Ni} / \mathrm{WC}$ alloy to produce an in-situ synthesized $\mathrm{WC} / \mathrm{TaC}$ reinforced composite coating on AISI 1045 mild steel substrate. The microstructure of the composite coating, distribution and morphology of each phase in the composite coating were discussed, and the micro-hardness of composite coating was also investigated.

\section{Experiment}

The specimens of AISI 1045 mild carbon steel plate with dimension of $55 \mathrm{~mm} \times 40 \mathrm{~mm} \times 10 \mathrm{~mm}$ were used as the substrate in experiments. The wide groove with dimension of $45 \mathrm{~mm} \times 40 \mathrm{~mm}$ and depth of $1 \mathrm{~mm}$ was machined by $\mathrm{CNC}$ milling machine for each specimen, and the upper surface of grooves were ground with sandpaper, and then cleaned with acetone prior to laser cladding. The powder mixtures of coating alloy were prepared from commercially available Ni60-3.5wt\%WC (Ni60, Shanghai Stellite Co., Ltd, China), Tantalum oxide $\left(\mathrm{Ta}_{2} \mathrm{O}_{5}, 99.5 \%\right.$ purity) and graphite $(99.5 \%$ purity). The composition of nickel-based alloy powder was listed in Table 1. In order to initiate the reaction $\left\{\mathrm{Ta}_{2} \mathrm{O}_{5}+7 \mathrm{C} \rightarrow\right.$ $2 \mathrm{TaC}+5 \mathrm{CO} \uparrow\}$, the tantalum oxide and graphite were mixed according to the stoichiometric proportion ratio of one to seven. After that, the $10 \mathrm{wt} \%$ mixed powder of tantalum oxide and graphite were added to Ni60-3.5wt\%WC and blended sufficiently in a mortar for about $1 \mathrm{~h}$. Then, the mixed powder was preplaced into the machined grooves by the thickness of 1 $\mathrm{mm}$ on the surface of substrate by adding rosin acetone binder and then dried in the oven for $2 \mathrm{~h}$ with temperature of $80{ }^{\circ} \mathrm{C}$.

The coating was produced by $\mathrm{HJ}-30003 \mathrm{~kW}$ continuous wave $\mathrm{CO}_{2}$ laser; the beam size was about $4 \mathrm{~mm} \times 6 \mathrm{~mm}$. The process parameters were determined based on the exploratory experiments of team: the input power was in range of 1800 $2100 \mathrm{~W}$, and the scanning speed was about $300 \mathrm{~mm} / \mathrm{min}$ with overlap of $50 \%$ for every track. During the process, the composite coating was shielded from oxidation in air by Argon gas.

After laser cladding, the cross section of samples coating was cut transversely by wire EDM and then polished according to the standard polishing procedures. The samples were etched using an etchant of $\mathrm{HCl}$ and $\mathrm{HNO}_{3}$ with volume

Table 1 Chemical composition of nickel-based alloy powder (wt\%)

\begin{tabular}{cccccc}
\hline $\mathrm{C}$ & $\mathrm{Si}$ & $\mathrm{B}$ & $\mathrm{Cr}$ & $\mathrm{Fe}$ & $\mathrm{Ni}$ \\
\hline 0.8 & 3.5 & 4.5 & 15.5 & 15 & Bal. \\
\hline
\end{tabular}

ratio of 1:3 for the examination of morphology. The microstructure of coatings and chemical elements was analyzed with JSM-6610 scanning electron microscope (SEM), while the composite of phase was revealed by means of energy dispersive spectroscopy (EDS) which was equipped with the SEM. The X-ray diffraction (XRD) was performed by BRUKER D8 ADVANCE at $4 \% \mathrm{~min}$, with $\mathrm{Cu} \mathrm{K} \alpha$ source. The microhardness was measured by an MVC-1000A Vickers microhardness tester under a load of $500 \mathrm{~g}$ for duration of $15 \mathrm{~s}$.

\section{Results and Discussion}

\subsection{Morphology of cladding surface}

The composite coating produced by laser cladding is shown in Fig.1. The composite coating has a good flat surface at the beginning of laser cladding, while it becomes coarse with further cladding process. This phenomenon may be caused by the accumulation of heat. Since the sample is relatively small in volume, the whole volume temperature will increase with continuous beam scanning. Therefore, the coating material is melt. Moreover, it is boiled to a certain high temperature, and the coating surface is fluctuated and coarse as a result.

\subsection{XRD analysis}

Fig. 2 shows the XRD pattern of the laser cladding coating of TaC/WC-modified nickel-based alloy. It is revealed that the diffraction peaks of possible phases are close, so it is difficult to identify the reflection in XRD patterns of the composite coating except for $\gamma$-(Ni, $\mathrm{Fe})$ and $\mathrm{TaC}$, and $\mathrm{Ni}_{2} \mathrm{~W}_{4} \mathrm{C}$ phase. One reason for this phenomenon is that the distance between these planar corresponded to diffraction peaks of possible phases in the coatings are close to each other. Another reason may be that the over-saturation and thus distortion of the lattice caused by non-equilibrium solidification involved in the laser cladding ${ }^{[5]}$. Nevertheless, indexed results of diffraction peak according to JCPDS show that the composite coating is mainly composed of $\gamma$-(Ni, $\mathrm{Fe}), \mathrm{TaC}, \mathrm{M}_{7} \mathrm{C}_{3}, \mathrm{Ni}_{2} \mathrm{~W}_{4} \mathrm{C}$ and $\mathrm{W}_{2} \mathrm{C}$. Fig. 2 indicates strong diffraction peak of $\mathrm{TaC}$, revealing that $\mathrm{TaC}$ can be formed by in situ reacting $\mathrm{Ta}_{2} \mathrm{O}_{5}$ with $\mathrm{C}$ in Ni-based alloy. Meanwhile, no diffraction peak of $\mathrm{WC}$ is found, indicating that the particles of WC are totally dissolved in process of laser cladding.

\subsection{Microstructure characterization}

Fig. 3 shows the electron images from transverse cross

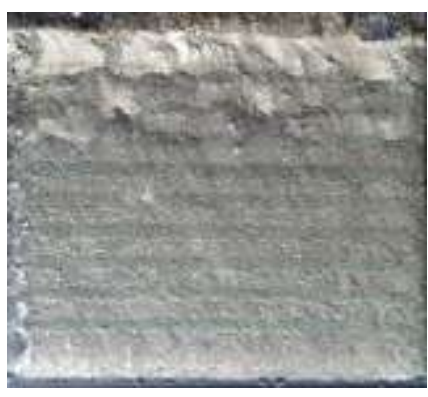

Fig. 1 Morphology of coating surface 


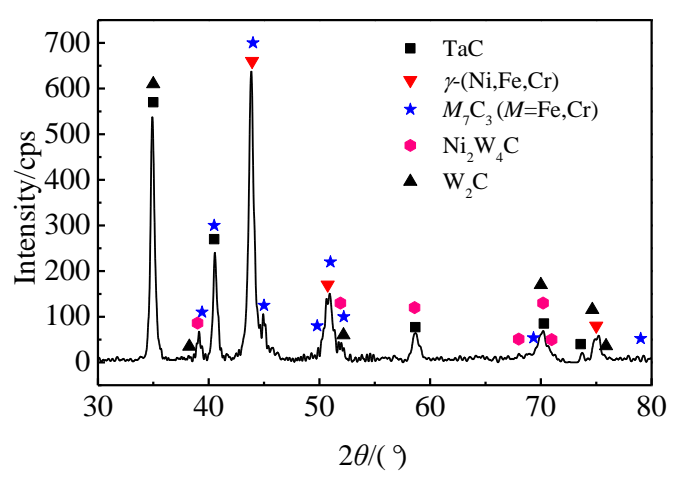

Fig. 2 XRD pattern of the laser cladding coating

section of $\mathrm{WC} / \mathrm{TaC}$ reinforced composite coatings on the AISI 1045 steel. The composite coating is free from cracks, pores and other inclusions, which reveals that the scanning parameters are appropriate in the study. Also, an excellent metallurgical bond exists between the coating and the steel substrate.

During laser scanning, the laser beam irradiates the mixed powder, and hence, powder melts and forms a molten pool. At the bottom of molten pool, the molten metal directly contacts the substrate. As a result, the molten metal is under large temperature gradient because of cooling function of substrate at the beginning of scanning. According to the principle of solidification, the microstructure of rapid cooling is dependent on the ratio between temperature gradient $\left(G_{\mathrm{L}}\right)$ and solidification velocity $(V)^{[15]}$. As the ratio of $G_{\mathrm{L}} / V$ increases, the dendrites will transform to cellar or planar structures, and form a band structure at the interface between coating and substrate. Far from the interface, the transition region of dendrites/cellar is thus formed along the thermal flux direction due to the increased velocity of thermal diffusion. At last, the microstructure totally transforms into dendrites. Under the disturbance of environmental, the ratio of $G_{\mathrm{L}} / V$ becomes small. Moreover, the non-oriented crystals will be formed.

Considering the characteristics of rapid solidification in laser cladding, the velocity of solidification approximately approaches scanning speed. In the light of thermal input model of laser cladding ${ }^{[16]}$ (Fig.4), the relationship is formulated as:

$$
v_{\mathrm{i}}=v_{\mathrm{Lb}} \cos \beta
$$

where, $\beta$ is angle between scanning speed of laser beam $v_{\mathrm{Lb}}$ and interfacial solidification velocity $v_{i}$. At the beginning of solidification, $\beta$ is close to $90^{\circ}$, and hence $v_{\mathrm{i}}$ is almost zero. Furthermore, extremely large ratio of $G_{\mathrm{L}} / V$ prompts formation of planar. With the further moving forward, a small ratio of $G_{L} / V$ causes that the carbides nucleate and grow rapidly. Meanwhile the high content elements in alloy increases degree of undercooling. Therefore, heterogeneous nucleation is dominant, which will intensify the accumulation of carbide surrounding by the much primary phases.

Fig. 5 shows the magnified electron image corresponding to the area marked by black frame in Fig 3b. According to the EDS results as shown in Table 2 and XRD analysis results, it is strongly suggested that grey area marked as $\mathrm{E}$ are $\gamma-(\mathrm{Ni}, \mathrm{Fe})$, whereas the content of $\mathrm{Fe}$ is quite high. Based on the formation mechanism of laser cladding, the following reason could be given. Under high laser beam scanning and relatively low scanning speed, high dilution may happen. Consequently, the excessively high $\mathrm{Fe}$ contents in coating come from ferrous substrate $^{[17]}$. It can be seen that some white blocky particle phases are embedded in the matrix, and the composition of white particle marked as A, B are shown in Table 2. The phases have fairly high content of Ta, so this phase would be confirmed as TaC combining with the results of XRD and Ref.[6]. Since the W-L (8.397 keV) and Ta-L (8.146 keV), W-M $(1.70 \mathrm{keV})$ and Ta-M $(1.77 \mathrm{keV})$ characteristic X-ray lines are in close proximity, EDS doesn't analyze the composite of coating precisely. Therefore, the high content of Ta may include some tungsten or tungsten carbide particles. The composition of $\mathrm{C}$ is also listed in Table 2. The result shows that there still are some Ta or W embedded in $\gamma$-Ni such as $\mathrm{Ni}_{2} \mathrm{~W}_{4} \mathrm{C}$ and $\mathrm{W}_{2} \mathrm{C}$. The coating still contains some coarse grey phases and dark phases (marked as point D in Fig.5), they are irregularly dispersed in the matrix, and its composition is listed in Table 2. This phase shows the needle-like morphologies and mainly contains $\mathrm{Cr}, \mathrm{Fe}$ and $\mathrm{C}$, so this phase may be $\mathrm{M}_{7} \mathrm{C}_{3}$ type carbide according to the XRD and SEM results.

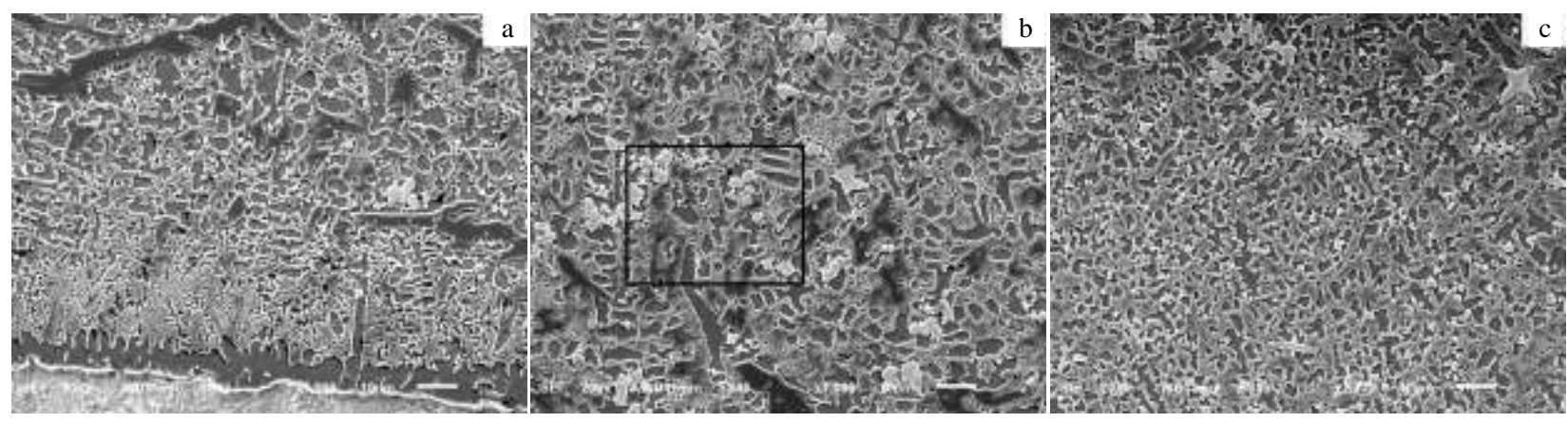

Fig. 3 Electron images of the WC/TaC/Ni60 coating from transverse cross-section: (a) bottom, (b) middle, and (c) upper 


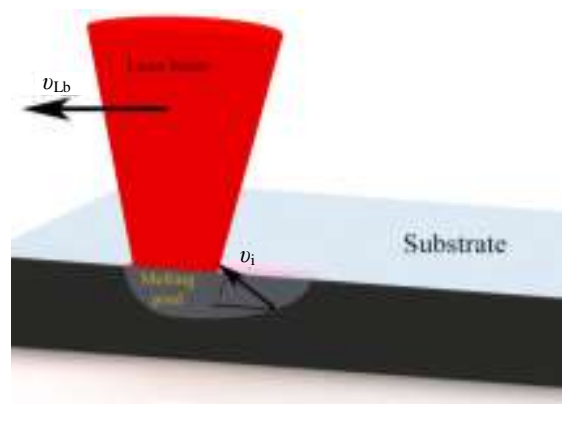

Fig. 4 Laser beam scanning speed and interface moving

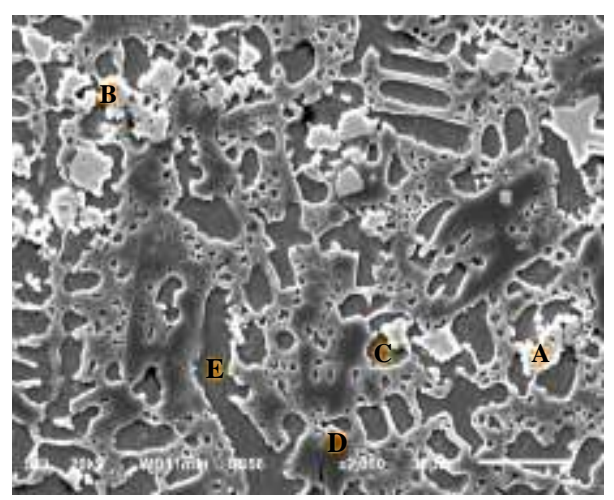

Fig.5 Magnified image corresponding to the area in Fig.3b

Table 2 Composition of marked zones in Fig. 5 by EDS analysis (wt\%)

\begin{tabular}{cccccccc}
\hline Zone & $\mathrm{C}$ & $\mathrm{Si}$ & $\mathrm{Cr}$ & $\mathrm{Fe}$ & $\mathrm{Ni}$ & $\mathrm{Ta}$ & $\mathrm{W}$ \\
\hline $\mathrm{A}$ & 12.5 & - & 2.38 & 2.58 & 5.08 & 77.25 & 0.21 \\
$\mathrm{~B}$ & 14.82 & - & 2.19 & 2.41 & 4.33 & 75.52 & 0.73 \\
$\mathrm{C}$ & 18.42 & 1.09 & 6.51 & 34.42 & 32.0 & 7.15 & 0.4 \\
$\mathrm{D}$ & 17.36 & - & 53.87 & 21.44 & 7.23 & - & 0.1 \\
$\mathrm{E}$ & 11.53 & 0.33 & 7.26 & 47.28 & 33.6 & - & - \\
\hline
\end{tabular}

\subsection{Formation of TaC}

Under the irradiation of laser beam, the powder melts and forms a molten pool rapidly, and the reaction would occur due to the negative Gibbs free energy for $\left\{\mathrm{Ta}_{2} \mathrm{O}_{5}+7 \mathrm{C} \rightarrow\right.$ $2 \mathrm{TaC}+5 \mathrm{CO} \uparrow\}$, which also means that the reaction can occur spontaneously. In range of 298 3000 K, the Gibbs free energy follows the relationship $G=-0.812 \mathrm{~K}+1144^{[18]}$, as plotted in Fig.6.

The reaction occurs as temperature exceeds $1380 \mathrm{~K}$. Due to high value of enthalpy in reaction, the amount of heat will be released, which may cause high dilution as well. The melting point of $\mathrm{TaC}$ is about $4100 \mathrm{~K}$. Hence, the $\mathrm{TaC}$ particles precipitate from molten pool. The density of $\mathrm{TaC}$ is about 14.3 $\mathrm{g} / \mathrm{cm}^{3}$, while that of $\mathrm{WC}$ is $15.6 \mathrm{~g} / \mathrm{cm}^{3}$. As a result, the WC and $\mathrm{TaC}$ could deposit but the former is faster than the latter due to the lower density of $\mathrm{Ni}\left(8.9 \mathrm{~g} / \mathrm{cm}^{3}\right)$. As well, under the convection of molten pool, the large particles have not enough

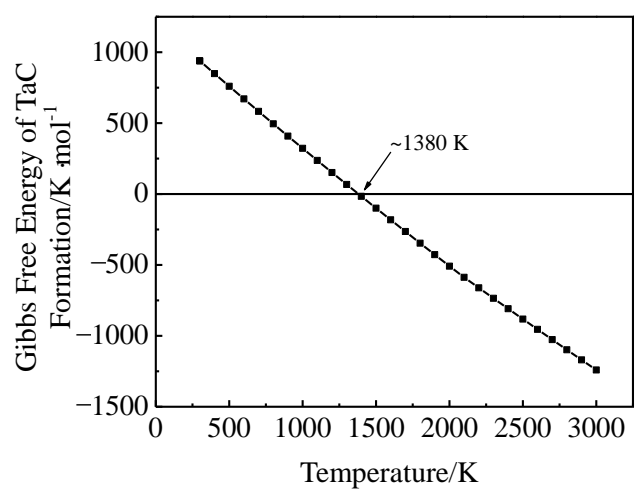

Fig. 6 Gibbs free energy of formation of $\mathrm{TaC}^{[18]}$

time to sink to bottom as the liquid becomes solid. Finally, the $\mathrm{TaC}$ particles accumulate in the middle section.

\subsection{Dissolution of WC}

Under high irradiation of laser beam, particle of WC will dissolute in case of temperature about $2776 \pm 10{ }^{\circ} \mathrm{C}$. WC has a better absorptivity for $\mathrm{CO}_{2}$ laser than other metal powder, and hence the temperature of molten pool is higher than that of dissolution of WC, combining with the capillary effect and heat generated by the high free formation enthalpy when $\mathrm{Ta}_{2} \mathrm{O}_{5}$ react with carbon ${ }^{[18]}$. The deposited $\mathrm{WC}$ in bottom will react as follows:

$$
\begin{aligned}
& \mathrm{WC} \rightarrow \mathrm{W}+\mathrm{C} \\
& \mathrm{W}_{2} \mathrm{C} \rightarrow 2 \mathrm{~W}+\mathrm{C} \\
& 2 \mathrm{WC} \rightarrow \mathrm{W}_{2} \mathrm{C}+\mathrm{C} \\
& \mathrm{W}_{2} \mathrm{C} \rightarrow \mathrm{WC}+\mathrm{W}
\end{aligned}
$$

The reaction (4) is easy to happen because of the low reaction Gibbs energy according to standard thermodynamic calculation $^{[19]}$. Based on equilibrium phase diagram of $\mathrm{Fe}-\mathrm{W}-\mathrm{C}$, the abundant $\mathrm{Fe}$ contents diffuse into the molten $\mathrm{Ni}$ alloy which accelerates the dissolution of WC particles, as a result, the WC particles are almost dissolved in bottom ${ }^{[20]}$. Pushed by interaction of dissolved WC and elements in $\mathrm{Ni}$ alloy, the eutectic carbide with low melting point would be formed as well. Meanwhile, the mass transfer under high speed convection of molten pool re-precipitates the presence of the decomposition of free state elements during solidification. Consequently, the micro-structure is changed. In the molten pool, the $\mathrm{W}_{2} \mathrm{C}$ is produced according to the reaction $2 \mathrm{WC} \rightarrow \mathrm{W}_{2} \mathrm{C}+\mathrm{C}$. However, $\mathrm{W}_{2} \mathrm{C}$ is meta stable. Thus, it is supposed that $\mathrm{W}_{2} \mathrm{C}$ combines free state carbon to form $\mathrm{Ni}_{2} \mathrm{~W}_{4} \mathrm{C}$ in molten $\mathrm{Ni}$ alloy.

Not only do the abundant free state tungsten disperse in molten pool after the dissolution of $\mathrm{WC}$, but also the carbondeficient areas appear after reaction of $\mathrm{Ta}_{2} \mathrm{O}_{5}$ with carbon. What's more, the undissolved WC particles have poor wettability to $\mathrm{Ni}$ and push the $\mathrm{Ni}$ together. From the equilibrium phase diagram of $\mathrm{W}-\mathrm{C}-\mathrm{Ni}^{[21]}$ shown in Fig.7, when the temperature 


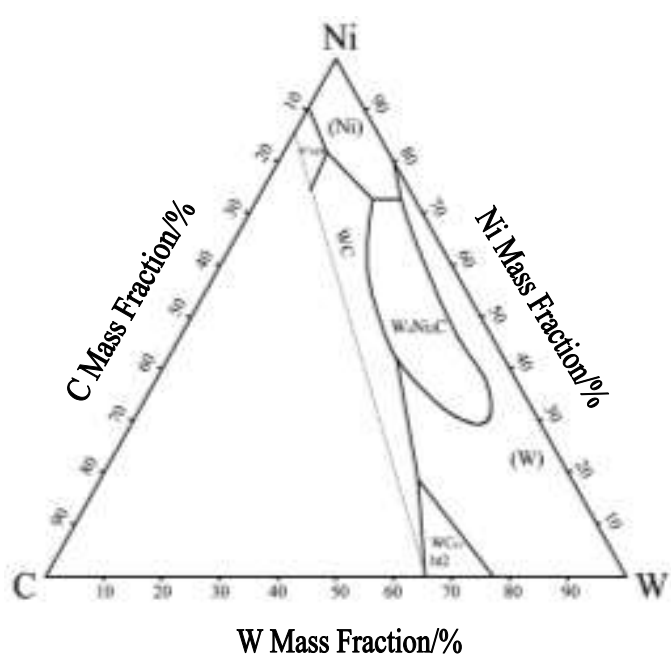

Fig.7 Phase diagram of W-Ni-C ${ }^{[21]}$

reaches to eutectic point of $\mathrm{WC}-\mathrm{Ni}$, the enrichment of $\mathrm{Ni}$ forms in carbon-deficient area under the dragging force because of capillary effect. Since the process is continuing, the repelled free state of tungsten and carbon are surrounding the rich $\mathrm{Ni}$ area, which provide the conditions to form the $\eta$-phase $\mathrm{Ni}_{2} \mathrm{~W}_{4} \mathrm{C}^{[22]}$. With the further decrease of temperature, the eutectic phase of $\mathrm{M}_{7} \mathrm{C}_{3}$ such as $\mathrm{Fe}_{7} \mathrm{C}_{3}$ and $\mathrm{Cr}_{7} \mathrm{C}_{3}$ grows significantly.

From Fig. 3, it is found that the distribution of $\mathrm{TaC}$ particles is not very uniform. The fine particles are embedded in the bottom and upper of coating, whereas many large particles accumulate and embed in the matrix in middle section. As mentioned above, this may be explained as follows. The particles with varied density deposit the possible area under the high speed convection and interaction among the particles. Consequently, the $\mathrm{TaC}$ particles are pushed or engulfed involving the interaction of solid/liquid interface (SLI). It is widely accepted that there exists a subcritical velocity ${ }^{[23-25]}$, which is determined by radius of particles, the ratio of thermal conductivity of liquid and particle, viscosity and interatomic spacing. When the velocity of the SLI is less than the critical velocity, the particles will be pushed, otherwise they will be engulfed. The outcomes in molten pool such as $\mathrm{Ni}, \mathrm{TaC}$ and tungsten have corresponding thermal conductivity of 91, 22.19 and $173 \mathrm{~W} / \mathrm{m} \cdot \mathrm{K}$, respectively. The analysis should take the coefficient $\alpha=K_{\text {particle }} / K_{\text {matrix }}$ into consideration, the SLI will sink when $\alpha>1$ and derived drag force will engulf particle. Whereas $\alpha \leqslant 1$, the particle will be expelled. For this $\mathrm{WC} / \mathrm{TaC}$ reinforced composite coating, the outcomes with high melting point in molten pool will be expelled by nickel alloy except for tungsten, the $\mathrm{TaC}$ and the related particles distribute as shown in Fig.3.

\subsection{Microhardness of coatings}

Fig. 8 illustrates the hardness distribution along the depth direction in the transverse cross section of the composite $\mathrm{Ni}-\mathrm{WC}+10 \mathrm{wt} \%\left(\mathrm{Ta}_{2} \mathrm{O}_{5}+\mathrm{C}\right)$ coatings and Ni60 coating, and all of the data are an average of three measurements.

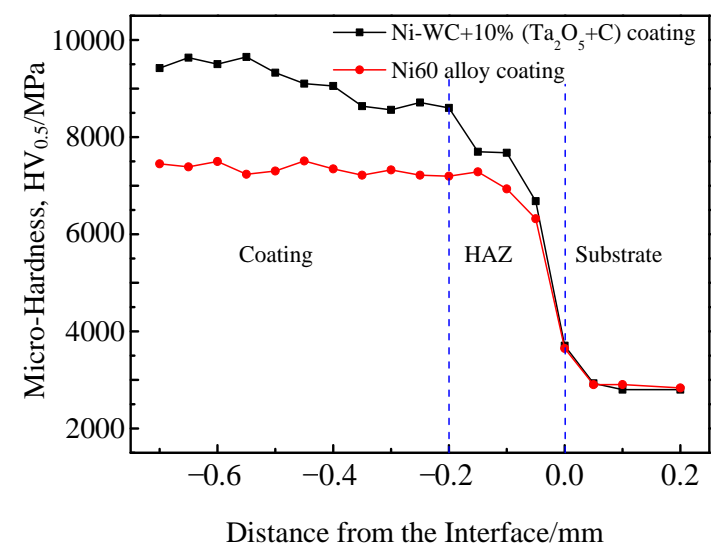

Fig.8 Microhardness distribution within composite coating

The coating hardness exhibits a stepwise profile and it can be divided into three obvious regions named as substrate, heat affect area (HAZ) and coating regions. The microhardness shows a rising tendency from bottom to top surface in the coatings, and there is a remarkable improvement and gives a high average hardness $\mathrm{HV}_{0.5}$ of $9650 \mathrm{MPa}$, which is 3 times of substrate and 1.3 times of Ni60 coating. This may attribute to the presence of amounts of hard $\mathrm{TaC}$ and $\mathrm{W}_{2} \mathrm{C}$ particles formed during cladding process. The fine particles of $\mathrm{TaC}$ and $\mathrm{W}_{2} \mathrm{C}$ are uniformly distributed in the upper coating corresponding to the highest hardness, while the uneven and accumulated particles represent a higher harness in the coating. Moreover, the coarse $\mathrm{M}_{7} \mathrm{C}_{3}$ carbides suppressed by in-situ $\mathrm{TaC}$ are also factors to improve the hardness. In the middle of coating, the hardness is lower slightly than that of upper. This results may be caused by the formation of $\eta$ phase of $\mathrm{Ni} 2 \mathrm{~W} 4 \mathrm{C}$, which can decrease the hardness of coating. At the bottom of coating, the microstructure mainly consists of $\gamma$-Ni solid solution and its hardness is lower, which is also influenced by the dilution of molten substrate. The hardness of HAZ is higher than that of substrate because of the transformation of martensitic transformation in the solidification of cladding process.

\section{Conclusions}

1) The in-situ synthesis of $\mathrm{WC} / \mathrm{TaC}$ reinforced nickel-based composite alloy has been produced on AISI 1045 carbon mild steel by laser cladding. The composite coating is free of cracks and pores and has a superior metallurgical bonding between the substrate and composite coating.

2) The microstructure experiences the planar, cellular and columnar dendrites. And the coating is mainly composed of $\gamma$-Ni dendrites, $\mathrm{W}_{2} \mathrm{C}, M_{7} \mathrm{C}_{3}$ carbides, and dispersed $\mathrm{TaC}$ particles. The $\mathrm{TaC}$ particles are formed and dispersed in the coating improving the hardness through the addition of $\left(\mathrm{Ta}_{2} \mathrm{O}_{5}+\mathrm{C}\right)$ into Ni-WC. The WC are almost dissolved in the coating, and prompt the formation of $\mathrm{Ni}_{2} \mathrm{~W}_{4} \mathrm{C}$ and $\mathrm{W}_{2} \mathrm{C}$. 
3) Compared to a Ni60 coating, the hardness $\mathrm{HV}_{0.5}$ of $\mathrm{WC} / \mathrm{TaC} / \mathrm{Ni60}$ composite coating is enhanced to a value similar to $9650 \mathrm{MPa}$. In the middle of coating, the hardness is dropped slightly by the $\mathrm{Ni}_{2} \mathrm{~W}_{4} \mathrm{C}$.

\section{References}

1 Vilar R. Journal of Laser Applications[J], 1999, 11(2): 64

2 Singh A, Dahotre N B. Metallurgical and Materials Transactions $A[\mathrm{~J}], 2005,36 \mathrm{~A}(3 \mathrm{~A}): 797$

3 Zhou Shengfeng, Zeng Xiaoyan, Hu Qianwu et al. Applied Surface Science [J], 2008, 255(5): 1646

4 Zhang Hui, Zou Yong, Zou Zengda et al. Journal of Alloys and Compounds[J], 2015, 622: 62

5 Dong Gang, Yan Biao, Deng Qilin et al. Rare Metal Materials and Engineering [J], 2011, 40(6): 973

6 Yu Ting, Deng Qilin, Dong Gang et al. Journal of Wuhan University of Technology, Materials Science Edition[J], 2013, 28(3): 437

7 Yang Sen, Liu Wenjin, Zhong Minlin. Journal of Materials Science \& Technology[J], 2006, 22(4): 519

8 Yu Ting, Deng Qilin, Dong Gang et al. Applied Surface Science [J], 2011, 257(11): 5098

9 Wang Wenli, Chao Mingju, Wang Dongsheng et al. Chinese Journal of Lasers[J], 2007, 34(2): 277 (in Chinese)

10 Chao Mingju, Wang Wenli, Liang Erjun et al. Surface and Coatings Technology[J], 2008, 202(10): 1918

11 Yu Ting, Deng Qilin, Zheng Jingfeng et al. Chinese Journal of
Lasers[J], 2011, 38(7): 0703001 (in Chinese)

12 Zhong Minlin, Liu Wenjin, Zhang Yu et al. International Journal of Refractory Metals \& Hard Materials[J], 2006, 24(6): 453

13 Pagounis E, Talvitie M, Lindroos V K. Metallurgical and Materials Transactions A[J], 1996, 27(12): 4171

14 Doğan Ö N, Hawk J A, Tylczak J H et al. Wear[J], 1999, 225-229(Part 2): 758

15 Tiller W A, Jackson K A, Rutter J W et al. Acta Metallurgica[J], 1953, 1(4): 428

16 Mohanty P S, Mazumder J. Metallurgical and Materials Transactions B[J], 1998, 29(6): 1269

17 Zhang Jian, $\mathrm{Hu} \mathrm{Yu}$, Tan Xiaojun et al. Transactions of Nonferrous Metals Society of China[J], 2015, 25(5): 1525

18 Barin I, Thermochemical Data of Pure Substances[M]. Germany: Wiley-VCH Verlag GmbH, 1995: 1587

19 Zhang Zhong, Liu Hongxi, Zhang Xiaowei et al. Advanced Materials Research[J], 2012, 430-432: 137

20 Yuan Xiaozhou, Dai Xiaoguang. Journal of Ningbo Polytechnic [J], 2013, 17(6): 106 (in Chinese)

21 Fiedler M L, Stadelmaier H H. Z Metallkd[J], 1975, 66: 402

22 Shi Kaihua, Zhou Kechao, Li Zhiyou et al. Transactions of Nonferrous Metals Society of China[J], 2015, 25(3): 873

23 Shangguan D, Ahuja S, Stefanescu D M. Metallurgical Transactions A [J], 1992, 23(2): 669

24 Stefanescu D M, Dhindaw B K. ASM Handbook[J], 1988, 15: 142

25 Abbas G, West D R F. Wear[J], 1991, 143(2): 353

\title{
原位生成 WC/TaC 复合激光熔覆层组织研究
}

\author{
雍耀维 ${ }^{1,2}$, 傅 卫 $^{3}$, 张 翔 $^{1}$, 邓琦林 ${ }^{1}$, 杨建国 ${ }^{1}$ \\ (1. 上海交通大学, 上海 200240) \\ (2. 宁夏大学, 宁夏 银川 750021)
}

(3. 哈尔滨工业大学 先进焊接与连接国家重点实验室, 黑龙江 哈尔滨 150001)

摘 要: 利用激光熔覆技术，将氧化钽和石墨的混合粉末添加到 Ni60 包 WC 的镍基合金粉末中，成功制备了 $\mathrm{TaC} / \mathrm{WC}$ 复合涂层。使用 扫描电镜(SEM)、X 射线衍射仪 (XRD) 等仪器分析了镍基合金复合涂层横断面的显微组织, 并对其硬度进行研究分析。结果表明在基体 与涂层之间形成了良好的冶金结合, 复合涂层不仅含有 $\gamma-\mathrm{Ni}$ 树枝晶、 $\mathrm{W}_{2} \mathrm{C} 、 M_{7} \mathrm{C}_{3}$ 、以及大量弥散分布的 $\mathrm{TaC}$ 颗粒。复合涂层的硬度 $\mathrm{HV}$ 可达 $9650 \mathrm{MPa}$, 是 $\mathrm{Ni60}$ 涂层的 1.3 倍, 这主要是因为 $\mathrm{TaC}$ 颗粒的分布促使其内部组织结构改变以及相变引起的硬度上升。 关键词：激光熔覆；镍基合金；钽; 碳化钽; 碳化铇

作者简介: 雍耀维, 男, 1980 年生, 博士生, 上海交通大学机械与动力工程学院, 上海 200240, E-mail: yywnxu@ 163.com 